\title{
Emergency Physicians' Perceived Influence of EHR Use on Clinical Workflow and Performance Metrics
}

\author{
Courtney A. Denton ${ }^{1}$ Hiral C. Soni ${ }^{2}$ Thomas G. Kannampallil ${ }^{3}$ Anna Serrichio ${ }^{1}$ Jason S. Shapiro ${ }^{4}$ \\ Stephen J. Traub ${ }^{5}$ Vimla L. Patel ${ }^{1,2}$
}

${ }^{1}$ Center for Cognitive Studies in Medicine and Public Health,

Address for correspondence Courtney A. Denton, The New York The New York Academy of Medicine, New York, New York, Academy of Medicine, 1216 Fifth Avenue, Room 454, New York, United States

${ }^{2}$ Department of Biomedical Informatics, Arizona State University, Phoenix, Arizona, United States

${ }^{3}$ Department of Family Medicine, University of Illinois at Chicago, Illinois, United States

${ }^{4}$ Department of Emergency Medicine, Icahn School of Medicine at Mount Sinai, New York, New York, United States

${ }^{5}$ Department of Emergency Medicine, Mayo Clinic, Phoenix, Arizona, United States

Appl Clin Inform 2018;9:725-733. NY 10037, United States

(e-mail: courtney.dentonhurlbut@mail.mcgill.ca).

\section{Abstract}

Keywords

- physician perception

- EHR

- meaningful use

- clinical performance

- emergency

department
Objective Over the last decade, electronic health records (EHRs) have shaped clinical practice. In this article, we investigated the perceived effects of EHR use on clinical workflow and meaningful use (MU) performance metrics.

Materials and Methods Semistructured interviews were conducted with $20(n=20)$ physicians at two urban emergency departments. Interview questions focused on time spent on EHR use, changes in clinical practices with EHR use, and the effect of MU performance metrics on clinical workflow. Qualitative coding using grounded theory and descriptive analyses were performed to provide descriptive insights.

Results Physicians reported that EHRs improved their clinical workflow, especially on MUrelated activities including door-to-doctor time and admit decision time. EHR use also affected physicians work efficiency, quality of care provided, and overall patient safety. Conclusion Physicians' perception of EHRs is likely to influence their practices. With negative perceptions of EHR usability problems, positive aspects of EHR use, including the influence on MU performance metrics, may be overridden.

\section{Background and Significance}

To encourage the adoption of electronic health records (EHRs), the Health Information Technology for Economic and Clinical Health (HITECH) Act offered financial incentives for the "meaningful use" (MU) of certified EHRs. ${ }^{1}$ This was based on the expectation that MU (i.e., comprehensive documentation and management of patient care) of an EHR can potentially improve the quality of care received. In response to HITECH, many health care organizations, including their emergency departments (EDs), incorporated EHR systems into their practices. Using the EHR, the MU performance metrics, such as door-to-doctor time and admit decision time, measured in the ED could

\footnotetext{
${ }^{*}$ To earn credit, visit AMIA for details.
}

received

April 7, 2018

accepted after revision

July 6, 2018 (c) 2018 Georg Thieme Verlag KG Stuttgart · New York
DOI https://doi.org/

$10.1055 / \mathrm{s}-0038-1668553$. ISSN 1869-0327. 
be automatically collected and used for internal quality monitoring.

Despite these intentions to improve care, a recent study found that providers who qualify for MU incentives may not necessarily provide higher quality of care. ${ }^{2}$ Furthermore, based on a survey of 2,033 physicians conducted by Emani et al, physicians expressed negative feelings regarding the MU of EHRs, with only $20 \%$ indicating that the MU of the EHR would improve the quality and efficiency of their care activities. ${ }^{3}$ This study also found that physician satisfaction regarding the EHRs used was significantly associated with their perceptions, where more satisfied physicians had more positive beliefs about $\mathrm{MU}^{3}$ Another study assessing the benefits and additional workload resulting from compliance with the MU program reported beneficial perceptions of MU requirements related to basic care; however, MU requirements related to more complex care was believed to be cumbersome. ${ }^{4}$ Moreover, perceptions of ease of EHR use associated with MU-related functions has been found to be high among features that have been more readily adopted, such as viewing laboratory reports, and low for features less commonly adopted, such as public health reporting. ${ }^{5}$ Such perceptions, or ways in which information and experiences are processed, understood, or interpreted, can provide guidance for designing health information technology.

Although EHRs have generally had a positive impact on clinical practice, $^{6}$ research has highlighted challenges regarding their use, including usability issues, ${ }^{7}$ alteration of shift time distribution, ${ }^{8-10}$ and challenges of managing the temporal order of workflow activities. ${ }^{11}$ Review of recent literature suggests that EHRs have altered clinical workflow, particularly in the EDs. ${ }^{12}$ That is, the series of steps required to complete a clinical activity, such as documentation of patient information or management of care with other providers, has been altered as EHRs often do not account for the dynamic nature of clinical activities in the clinical environment.

The demands on ED clinicians require technology that supports their task efficiency and accuracy, especially during peak patient loads. ${ }^{13,14}$ Studies investigating the impact of EHR use on clinical workflow patterns have suggested that the time spent on documentation has increased over the last decade, ${ }^{15}$ with 50 to $65 \%$ of time being spent on EHR-related activities. ${ }^{13,16-18}$ In the ED, measurement of MU performance metrics can provide insights into these growing documentation requirements. However, it is important to keep in mind that reduction to metrics, such as door-todoctor time and admit decision time, was not the intention of EHR adoption or the MU program.

In this study, we investigate the relationships between physician perceptions of workflow as a result of EHR use and MU performance metrics. By investigating the role of two distinct EHRs in environments with different clinical workflows, levels of awareness of MU performance metrics, and histories of EHR usage, a foundation for evaluation of systemspecific and system-invariant patterns can potentially be identified.

\section{Materials and Methods}

\section{Setting and Participants}

This study was conducted at the EDs of Icahn School of Medicine at Mount Sinai in New York, New York, United States (referred to as Site 1) and Mayo Clinic in Phoenix, Arizona, United States (referred to as Site 2). Site 1 is an urban, academic hospital with a 44-bed adult ED unit that serves approximately 100,000 patients annually. Approximately $27 \%$ of ED patients are admitted to the hospital. Site 2 is also an urban hospital with a 24-bed ED (and 9 additional hallway beds) serving approximately 33,000 patients a year. About $50 \%$ of ED patients are admitted to the hospital.

To deal with high patient volumes, Site 1 utilizes a splitflow model. ${ }^{19}$ This model reduces the time patients wait to see care providers, potentially improving patient satisfaction and decreasing the likelihood that a patient will leave before being seen by a clinician. Site 2 utilizes a patient assignment tool to streamline ED workflow; this system uses a rotational assignment tool to distribute patients across available physicians. ${ }^{20}$ Each physician is assigned four patients at the start of their shift; from the fifth patient onwards, patients are assigned as per the physician's progress with other patients and availability. Both sites utilized distinct commercial EHRs and provided EHR training to physicians.

Participants for this study were board certified attending $(n=14)$ and resident $(n=6)$ ED physicians. Physicians were recruited through presentations at biweekly faculty and resident meetings. The institutional review boards of both hospitals and The New York Academy of Medicine approved this study. Written consents were obtained from all participants.

\section{Data Collection}

In this prospective observational study, conducted over an 8month period (February-October 2016), we used face-toface, semistructured interviews as the primary data collection method. Interview questions (see - Appendix A) were developed based on discussions with ED physicians during a preliminary pilot study, and with physician and nurse consultants from both study sites.

Each interview had four sections with participant demographics, prior EHR experiences, ED-specific MU performance metrics, and clinical workflow: (1) physician demographics including information about their role and experience, (2) implementation and EHR use questions on physicians' previous EHR experience and their perceptions regarding their current EHR, and (3) physicians' awareness of ED-specific MU performance metrics and their impact on clinical workflow. This was followed by questions regarding the physicians' perception about the EHR's influence on four MU performance metrics they were exposed to at the time of the interview (see -Table 1 for the ED-specific MU metrics ${ }^{21}$ ), and (4) perceptions about EHR impact on efficiency of clinical workflow, quality of care, and patient safety were also collected.

For this part of the interview, physicians were also asked to rate their EHR's impact on each of the categories using a 1 
Table 1 ED-specific MU metrics 21

\begin{tabular}{|l|l|l|}
\hline $\begin{array}{l}\text { National Quality } \\
\text { Forum no. }\end{array}$ & MU metric & Definition \\
\hline ED-005-08 & Door-to-doctor time & Median time from patient's first entry to being seen by an ED physician \\
\hline ED-003-08 & Admit decision time & Median time from patient's first entry to hospital admission decision \\
\hline ED-001-08 & Boarding time & Median time from patient's entry to their ED departure to an inpatient floor \\
\hline ED-006-08 & Walk out rate & Patients who leave the ED without being seen \\
\hline
\end{tabular}

Abbreviations: ED, emergency department; MU, meaningful use.

to 10 Likert scale (1 representing a low impact, and 10 a high impact). Finally, physicians were asked to describe any other relevant topics that were deemed important during the conversation.

Face-to-face interviews were conducted by coauthors (C.A.D. and H.C.S.). Each interview lasted approximately 45 minutes and were audiorecorded and transcribed for further analysis.

\section{Data Analysis}

Using the grounded theory approach for qualitative data analysis, ${ }^{22}$ interview transcripts from both sites were evaluated line-by-line to identify emerging themes. To achieve thematic saturation, our initial codebook-identified themes related to perceptions of EHR, usability concerns, and the EHR's influence on workflow efficiency, quality of care, and patient safety were developed. These codes were reanalyzed to examine relationships between them to develop higherlevel thematic categories, including perceptions regarding EHR, usability issues, EHR's impact on various factors, and MU awareness.

Attending and resident physician participants were grouped together for this analysis based on the similarities in their clinical responsibilities and their use of EHRs. With assistance from clinician collaborators, three researchers (coauthors C.A.D., H.C.S., and A.S.) independently coded the transcripts line-by-line using Microsoft Excel. After initial coding, using a subset of three transcripts ( $15 \%$ of sample), an interrater agreement was calculated. There was an $84 \%$ overlap across the three coders, showing high degree of agreement. All coding disagreements were then discussed and resolved, and agreement reached $100 \%$. The remaining transcripts (i.e., $n=17$ ) were then recoded using the updated codebook agreed upon during the resolution of disagreements.

Descriptive statistical methods were used to obtain frequencies and means for themes using Microsoft Excel, SPSS, and SAS 9.4.

\section{Results}

Twenty physicians $(n=20)$ were interviewed (Site 1: attending physicians, $n=4$, and residents, $n=6$; Site 2: attending physicians, $n=10$ ). The mean physician EHR experience at Site 1 was 3.1 years (standard deviation [SD] $=2.4)$, and that of Site 2 was 7.3 years $(S D=2.6)$.
Seven thematic categories (detailed explanation and examples are provided in -Appendix B) were identified. These included perceptions of EHR system, perceived time spent on clinical care, EHR usability issues, influence of EHR use on workflow efficiency, on quality of care and patient safety, as well as on four MU performance metrics.

\section{Perceptions of EHR and Usability Concerns}

There were several EHR usability concerns reported, and the most prominent concern was the "number of clicks" required to complete tasks (51\%), which is consistent with previous research. ${ }^{7}$ One physician (\#10; Site 1) noted that their system was "very functional, and yet it [has] too many clicks to get to key functions that we need in the emergency department, so it's robust, but it's not streamlined." This physician emphasized a lack of heuristics or shortcuts within the system design, which may lead to increased number of clicks, higher time consumption, and a need for assistance to complete the task (e.g., asking a colleague to locate a function). Abundance of clicks was the prominent usability issue, followed by multiple steps (and windows) to complete tasks. Another physician noted that “...sometimes there's a lot of stuff that I feel is not necessary, but I'm assuming it's there because it's necessary for someone else, not me" (\#3, Site 1). It was also reported that, "I['d] love to just be able to open the EKG in chart completion, but we can't, we have to go into the chart and then EKG, and then go into the charting function and then write it and then sign" (\#10, Site 1).

Other usability concerns included navigation (18\%), access to information (8\%), repetition of tasks (8\%), screen clutter (8\%), and multiple windows (6\%). One physician explained, "Going in and out of the patient's chart multiple times" can result in "being lost in it [the patient chart] and having to find things over and over again rather than having them easily found" (\#12, Site 2). Furthermore, the impact of EHR use on workflow and cognitive load was summarized by a physician as: "due to multiple steps in placing an order, [for example], time adds up and requires more [physician] attention" (\#13, Site 2). See - Table 2 for more illustrative examples of usability concerns at each study site.

With these usability concerns in mind, physicians reported on a 10-point scale that their EHRs supported patient safety (9), followed by quality of care (7.3), and, finally, efficiency of task completion (6.7). 
Table 2 Illustrative examples of usability concerns

\begin{tabular}{|c|c|c|}
\hline & Site $1(n=10)$ & Site $2(n=10)$ \\
\hline Usability concern & Responses & Responses \\
\hline Clicks & $\begin{array}{l}\text {...very functional, and yet it [has] too many clicks } \\
\text { to get to key functions that we need in the } \\
\text { emergency department, so it's robust, but it's } \\
\text { not streamlined" }\end{array}$ & $\begin{array}{l}\text { And there's no real shortcuts other than finding } \\
\text { it [the information] with the mouse and then } \\
\text { clicking it. It doesn't make any sense to me }\end{array}$ \\
\hline Accessing information & - & $\begin{array}{l}\text {...sometimes you just can't find what you're } \\
\text { looking for and you've got to get help to figure } \\
\text { out }\end{array}$ \\
\hline Navigation & $\begin{array}{l}\text {...sometimes [it is] kind of difficult to find those } \\
\text { [patient] orders and you have to click a couple of } \\
\text { different tabs }\end{array}$ & $\begin{array}{l}\text { Going in and out of the patient's chart multiple } \\
\text { times can result in being lost in it [the patient } \\
\text { chart] and having to find things over and over } \\
\text { again rather than having them easily found }\end{array}$ \\
\hline Repetitive tasks & - & $\begin{array}{l}\text { When searching [patient notes, the system ends } \\
\text { up] repopulating every single time }\end{array}$ \\
\hline Multiple windows & $\begin{array}{l}\text { l'd love to just be able to open the EKG in chart } \\
\text { completion, but we can't, we have to go into the } \\
\text { chart and then EKG, and then go into the } \\
\text { charting function and then write it and then sign }\end{array}$ & $\begin{array}{l}\text { Due to multiple steps in placing an order, time } \\
\text { adds up and requires more attention }\end{array}$ \\
\hline Screen clutter & $\begin{array}{l}\text {...sometimes there's like a lot of stuff that I feel } \\
\text { like is not necessary, but I'm assuming it's there } \\
\text { because it's necessary to someone else, not me }\end{array}$ & $\begin{array}{l}\text { The }[E H R] \text { templates look like "an order from a } \\
\text { restaurant" - abbreviated information without } \\
\text { any flow }\end{array}$ \\
\hline
\end{tabular}

Abbreviations: EHR, electronic health record; EKG, electrocardiography.

Influence of EHR Usability on Meaningful Use Metrics Half of the physicians (50\%) acknowledged that they were familiar with the ED MU metrics. When asked about the EHR's role in improving MU metrics, physicians reported a neutral-to-positive influence on their performance, with a perceived relationship between EHR use and both door-todoctor time and in admit decision time (see - Fig. 1).

A physician (\#9; Site 1) explained that "the process of patient input in the department has probably improved." However, three additional factors were also identified as improving workflow, including timeliness in the access of information, the respective workflows of the ED, and patient load. Physicians reported that the established workflow influenced MU metrics more than the EHR used. For example, one physician (\#14; Site 2) identified the patient assignment tool's role in improving MU metrics, explaining that the "Patient assignment system [has] decreased LOS [length of stay] as patient ownership is defined from the start...EHR 2 refinements may or may not help with this." From this physician's perspective, the algorithm with which patients are assigned to clinicians is believed to aid in reducing length of stay with improvements to the EHR not necessarily having

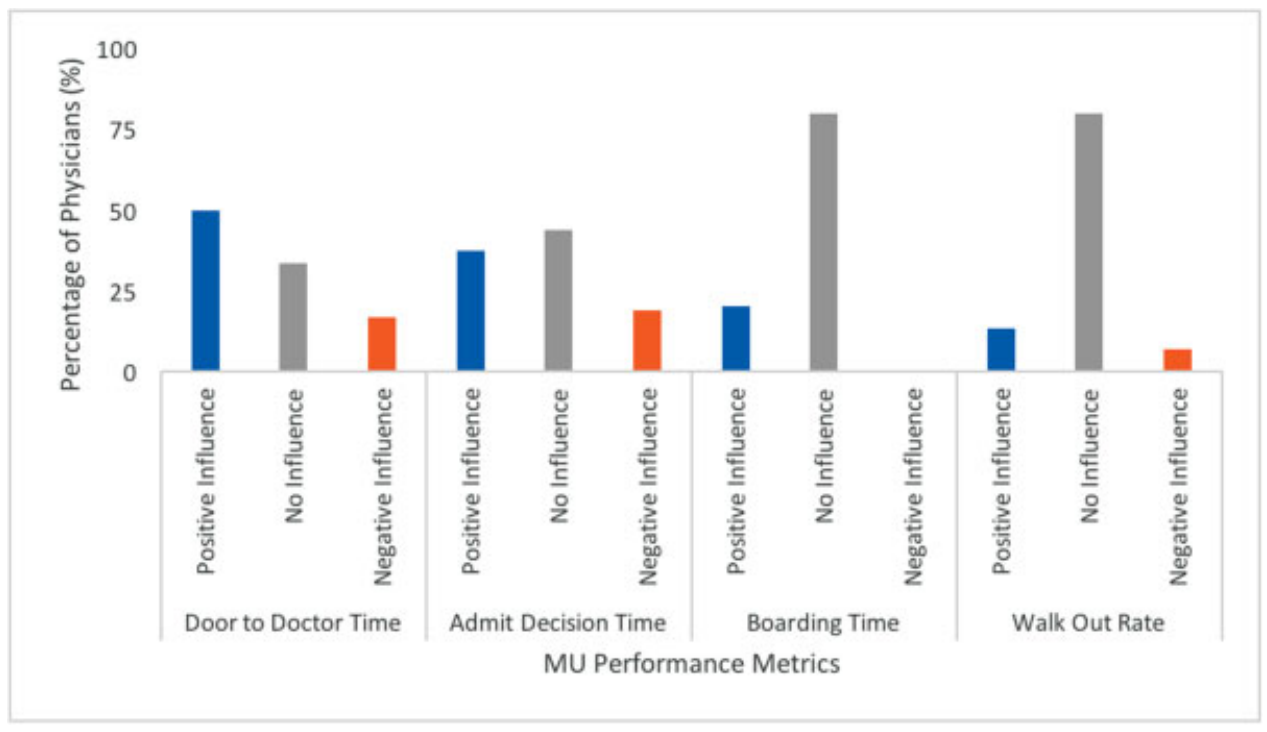

Fig. 1 Physician perceptions of electronic health record impact on meaningful use (MU) performance metrics. 
Table 3 Illustrative examples of EHR's influence on MU metrics

\begin{tabular}{|c|c|c|}
\hline Influence & Site $1(n=10)$ & Site $2(n=10)$ \\
\hline & Participant responses & Participant responses \\
\hline \multicolumn{3}{|c|}{ Door-to-doctor time } \\
\hline Positive & [in text] & $\begin{array}{l}\text { We have the ability to look up their medical records } \\
\text { before we even actually see the patient. I think that it } \\
\text { helps in that regard }\end{array}$ \\
\hline Neutral & I don't think it is changing the time people wait & $\begin{array}{l}\text { There is influence and decreased time, but because of } \\
\text { the patient assignment system, not the EHR }\end{array}$ \\
\hline Negative & $\begin{array}{l}\text { (The EHR) is probably still extending some of our } \\
\text { metrics because it takes so much time rather } \\
\text { than helping us }\end{array}$ & $\begin{array}{l}\text { If I'm taking more time to document on patients, I'm } \\
\text { not seeing the other patients that come in a timely } \\
\text { manner }\end{array}$ \\
\hline \multicolumn{3}{|c|}{ Admit decision time } \\
\hline Positive & $\begin{array}{l}\text { Being able to see their (the patient's) whole } \\
\text { record and know what's going on has definitely } \\
\text { made decision making go much more quickly }\end{array}$ & $\begin{array}{l}\text { Ordering what I feel is necessary, earlier in the process } \\
\text { will decrease door to decision time quite a bit }\end{array}$ \\
\hline Neutral & I don't think the system matters & $\begin{array}{l}\text { [EHR 2] does not have much impact, but the workflow } \\
\text { and getting laboratories and reports back does }\end{array}$ \\
\hline Negative & - & $\begin{array}{l}\text { Patient registration time to decision time is worst } \\
\text { because [EHR 2] slows down most workflows }\end{array}$ \\
\hline \multicolumn{3}{|c|}{ Boarding time } \\
\hline Positive & $\begin{array}{l}\text { I think the EMR does help with boarding... I no } \\
\text { longer take care of them. I talk to the inpatient } \\
\text { floor upstairs, and that care has been trans- } \\
\text { ferred, and the inpatient team is able to actually } \\
\text { manage them through the EMR }\end{array}$ & $\begin{array}{l}\text { [EHR 2's] a helpful tool once you know how to use it. It } \\
\text { does help me decrease the time the patient would } \\
\text { spend in the ED }\end{array}$ \\
\hline Neutral & [in text] & [in text] \\
\hline Negative & - & - \\
\hline \multicolumn{3}{|c|}{ Walk out rate } \\
\hline Positive & $\begin{array}{l}\text { I think the EHR has probably had some impact on } \\
\text { that as well because from the moment the } \\
\text { patient registers, we are able to track their } \\
\text { location and progress through the department a } \\
\text { lot more efficiently that we did before }\end{array}$ & I guess it's better than if it was on paper \\
\hline Neutral & $\begin{array}{l}\text { I'm not sure if you can say that (EHR } 1 \text { ) itself is } \\
\text { influencing walk out rate, but the fact that it is } \\
\text { publicly appointed as part of Meaningful Use } \\
\text { made us focus on it }\end{array}$ & I think that's actually probably the same \\
\hline Negative & - & $\begin{array}{l}\text { I think it slows things down (...) because I'm docu- } \\
\text { menting through an EHR and patients are not getting } \\
\text { back as quickly and I'm less efficient }\end{array}$ \\
\hline
\end{tabular}

Abbreviations: ED, emergency department; EHR, electronic health record; EMR, electronic medical record; MU, meaningful use.

a positive influence on reducing this metric. - Table 3 provides some illustrative examples of physician responses.

\section{EHR Use and Time Spent with Patients}

Site 1 physicians reported that they spent the same amount of time for direct patient care activities, utilizing their EHR system to perform indirect patient care, as compared with their previous experiences, including with paper-based systems. On average, $89 \%$ of the physicians reported that they spent considerably less time with patients, followed by $13 \%$ who spent about equal time in direct patient care and performing indirect patient care activities using the EHR system.

\section{Discussion}

Based on the semistructured interviews with physicians, EHR usability concerns appeared to be disruptors of physician perception of EHRs, potentially affecting their workflow. Although both sites used distinct EHR systems, the need for an abundance of clicks to perform routine tasks was a key issue at both locations. These perceived issues can potentially lead to more effort and time required to complete patient care tasks, and reduced direct patient care time. As suggested in recent literature, changes in the distribution of shift time ${ }^{8-10}$ as well as challenges managing the temporal order of workflow activities ${ }^{11}$ can decrease levels of user 
satisfaction and lead to physician burnout. ${ }^{23}$ With increased documentation requirements as a result of $\mathrm{MU}$, a change in the physician-patient relationship has also likely decreased both physician and patient satisfaction. ${ }^{24}$ It is also possible that decreased time at the bedside could lead to increased errors or decreased quality, thus compromising patient safety.

We found that EHR use potentially influenced the efficiency of physicians' workflow, the perceived quality of care they provided, and, consequently, the safety of patients. Perception of the EHR's influence can be, in general, traced to the physician perspectives regarding their EHR: for example, negative perceptions about the EHR were often related to EHR usability concerns. Furthermore, physician perspectives are indicative of their beliefs about the quality of the system used and the role of the EHR in supporting efficiency in the ED.

MU performance metrics are a measure of efficiency, whereas EHR use and workflow elements, such as splitflow organization and the patient assignment tool, are a means to improve care delivery. Reduction of MU performance metrics, including door-to-doctor time and admit decision time, were not intended goals of EHR adoption or the MU program. However, physicians who had an understanding of these performance metrics, perceived their EHR use to have been helpful in improving overall ED performance. As is suggested in the literature, more commonly adopted EHR features, which also may be better understood by the physician, are viewed in a positive light for clinical practice. ${ }^{5}$ These features may also be linked to basic care, contributing to the ease of use experienced by the physician. ${ }^{4,5}$

The complex demands of the ED environment require technology that supports clinician task efficiency and accuracy. Hence, the need of more standardized and user-centered designs that can accommodate for physician needs also aligning with the organization's workflow to provide care with ease. As a part of a larger research program, this study situates exploration of the MU program and the EHR's influence on clinical workflow through investigations using EHR data logs, ${ }^{25}$ sensor-based technology, ${ }^{26}$ ethnographic observations, and data visualizations. ${ }^{27}$

\section{Conclusion}

Physicians perceived that the use of EHRs improved clinical workflow, especially activities related to reducing door-todoctor time and admit decision time. These perceptions of the quality of the EHRs used relates to the extent to which they feel the system changes the way they complete their daily tasks. EHRs should decrease ED throughput time, increase patient satisfaction, and decrease ED crowding. However, usability concerns continue to be a contributor to negative perceptions of EHR use, overshadowing any problems related to MU performance metrics. As efficiency of workflow increases with the implementation of health information technologies and workflow organizations, we have to make sure that effectiveness and safety are not compromised.

\section{Limitations}

Attending and resident physician participants were grouped together for this analysis based on the similarities in their clinical responsibilities and their use of EHRs as our focus was on the general understanding of MU performance metrics. Although trained researchers collected data at each of the two study sites, it was relatively challenging to be completely consistent in data collection. We achieved what we consider thematic saturation; however, additional variance could have been minimized with a larger sample.

\section{Clinical Relevance Statement}

Given the interrelation between perception and cognition, a physicians' perception of EHRs is likely to influence how they think about their practices. Negative perceptions of EHR usability problems may override positive aspects of EHR use, including the influence on MU performance metrics, and contribute to decreased care satisfaction and physician burnout.

\section{Multiple Choice Questions}

1. Although EHRs have had positive impacts on clinical practice, research has also highlighted how EHRs have altered clinical workflow. EHR-related alterations of clinical workflow can best be described as changes to the:

a. Number of times a task is completed each day.

b. Level of physician and/or patient satisfaction.

c. Location where tasks are completed.

d. Sequential order in which tasks are executed.

Correct Answer: The correct answer is option d. Since clinical workflow is characterized by the series of required tasks to complete an activity, alterations to the order in which tasks are completed may impact other tasks (e.g., cause delays). Implementation of EHRs most dramatically influenced clinicians' documentation and review of patient information. Carayon and colleagues ${ }^{11}$ described the shift between pre-and post EHR implementation, where greater rates of team communication and order management prefaced clinical documentation and review by attending physicians than during observations of the paper-based system.

2. Quantitative studies investigating the impact of EHR use on clinical workflow patterns have suggested that about 50 to $65 \%$ of shift time is spent on EHR-related activities. Qualitative explorations (such as interviews) of workflow can situate these trends in real context. According to the authors, which of the following best indicates how physician perceptions inform future design of health information technologies? Perceptions provide insight about the:

a. EHR's role in supporting efficiency.

b. EHR's role in team interactions.

c. Variations in EHR-related activities.

d. Variations in the quality of the EHR used.

Correct Answer: The correct answer is option a. EHR usability concerns appear to be vital disruptors of physician 
perception of EHR, ultimately affecting the workflow. Hence, the need of more standardized and user-centered designs that can accommodate for physician needs and align with the organization's workflow to provide efficient care with ease. As the literature suggests, more commonly adopted EHR features, which also may be better understood by the physician, are viewed in a positive light for clinical practice. These features may also be linked to basic care, contributing to the ease of use experienced by the physician. Tailored training based on an organization's workflow may reduce the impact usability concerns have on EHR use.

\section{Protection of Human and Animal Subjects}

The institutional review board of the hospitals (Icahn School of Medicine at Mount Sinai, Mayo Clinic) and that of The New York Academy of Medicine approved this study. Written consents were obtained from all participants.

\section{Funding}

This research is supported by a grant (No. R01HS022670) from the Agency for Healthcare Research and Quality (AHRQ). The content is the sole responsibility of the authors and does not necessarily represent the official views of $A H R Q$.

\section{Conflict of Interest}

None.

\section{Acknowledgment}

We thank our clinical research team, Gloria Nimo, Cindy Clesca, and Joy Few, for their support in data collection; and Lu Zheng for help with data analysis.

\section{References}

1 Classen DC, Bates DW. Finding the meaning in meaningful use. N Engl J Med 2011;365(09):855-858

2 Samal L, Wright A, Healey MJ, Linder JA, Bates DW. Meaningful use and quality of care. JAMA Intern Med 2014;174(06):997-998

3 Emani S, Ting DY, Healey M, Lipsitz SR, Karson AS, Bates DW. Physician beliefs about the meaningful use of the electronic health record: a follow-up study. Appl Clin Inform 2017;8(04):1044-1053

4 Holman GT, Waldren SE, Beasley JW, et al. Meaningful use's benefits and burdens for US family physicians. J Am Med Inform Assoc 2018;25(06):694-701

5 Furukawa MF, King J, Patel V. Physician attitudes on ease of use of EHR functionalities related to Meaningful Use. Am J Manag Care 2015;21(12):e684-e692

6 Buntin MB, Burke MF, Hoaglin MC, Blumenthal D. The benefits of health information technology: a review of the recent literature shows predominantly positive results. Health Aff (Millwood) 2011;30(03):464-471

7 Middleton B, Bloomrosen M, Dente MA, et al; American Medical Informatics Association. Enhancing patient safety and quality of care by improving the usability of electronic health record systems: recommendations from AMIA. J Am Med Inform Assoc 2013;20(e1):e2-e8

8 Park SY, Lee SY, Chen Y. The effects of EMR deployment on doctors' work practices: a qualitative study in the emergency department of a teaching hospital. Int J Med Inform 2012;81(03): 204-217

9 McDonald CJ, Callaghan FM, Weissman A, Goodwin RM, Mundkur $M$, Kuhn T. Use of internist's free time by ambulatory care Electronic Medical Record systems. JAMA Intern Med 2014;174 (11):1860-1863

10 Sinsky C, Colligan L, Li L, et al. Allocation of physician time in ambulatory practice: a time and motion study in 4 specialties. Ann Intern Med 2016;165(11):753-760

11 Carayon P, Wetterneck TB, Alyousef B, et al. Impact of electronic health record technology on the work and workflow of physicians in the intensive care unit. Int J Med Inform 2015;84(08):578-594

12 Clarke MA, Steege LM, Moore JL, Belden JL, Koopman RJ, Kim MS. Addressing human computer interaction issues of electronic health record in clinical encounters. In: International Conference of Design, User Experience, and Usability. Springer; 2013:381-390

13 Chisholm CD, Weaver CS, Whenmouth L, Giles B. A task analysis of emergency physician activities in academic and community settings. Ann Emerg Med 2011;58(02):117-122

14 Handel DA, Hackman JL. Implementing electronic health records in the emergency department. J Emerg Med 2010;38(02):257-263

15 Perry JJ, Sutherland J, Symington C, Dorland K, Mansour M, Stiell IG. Assessment of the impact on time to complete medical record using an electronic medical record versus a paper record on emergency department patients: a study. Emerg Med J 2014;31 (12):980-985

16 Hill RG Jr, Sears LM, Melanson SW. 4000 clicks: a productivity analysis of electronic medical records in a community hospital ED. Am J Emerg Med 2013;31(11):1591-1594

17 Mamykina L, Vawdrey DK, Stetson PD, Zheng K, Hripcsak G. Clinical documentation: composition or synthesis? J Am Med Inform Assoc 2012;19(06):1025-1031

18 Neri PM, Redden L, Poole S, et al. Emergency medicine resident physicians' perceptions of electronic documentation and workflow: a mixed methods study. Appl Clin Inform 2015;6(01):27-41

19 Harris M, Wood J. Resuscitate ED metrics with split-flow design. Healthc Financ Manage 2012;66(12):76-79

20 Traub SJ, Bartley AC, Smith VD, Didehban R, Lipinski CA, Saghafian S. Physician in Triage Versus Rotational Patient Assignment. J Emerg Med 2016;50(05):784-790

21 National Quality Forum. National Voluntary Consensus Standards for Emergency Care - Phase II: Hospital-based Emergency Department (ED) Candidate Consensus Standards [PDF document]. Available at: https://www.qualityforum.org/Projects/e-g/Emergency_Care/tbEDIIcandidatemeasures.aspx. Accessed July 21, 2018

22 Strauss A, Corbin JM. Basics of Qualitative Research: Grounded Theory Procedures and Techniques. Thousand Oaks, CA: Sage Publications, Inc.; 1990

23 Asplin BR, Magid DJ, Rhodes KV, Solberg LI, Lurie N, Camargo CA Jr. A conceptual model of emergency department crowding. Ann Emerg Med 2003;42(02):173-180

24 Marmor RA, Clay B, Millen M, Savides TJ, Longhurst CA. The impact of physician EHR usage on patient satisfaction. Appl Clin Inform 2018;9(01):11-14

25 Kannampallil TG, Denton CA, Shapiro JS, Patel VL. Efficiency of emergency room physicians: insights from an observational study using EHR log files. Appl Clin Inform 2018;9(01):99-104

26 Frisby J, Smith V, Traub S, Patel VL. Contextual Computing: a Bluetooth based approach for tracking healthcare providers in the emergency room. J Biomed Inform 2017;65:97-104

27 Soni HC, Vankipuram A, Denton CA, Shapiro JS, Traub SJ, Patel VL. Characterization of Clinical Workflow and Electronic Health Records in Emergency Medicine. Presented at AMIA 2018 Clinical Informatics Conference, May 9th, 2018, Scottsdale, AZ 


\section{Appendix A}

\section{Semistructured Interview Questions: Role of EHR and Mean- ingful Use Requirements in Clinical Workflow in the ER}

The primary goal of this interview is to understand the nature of your work within the ED with respect to the EHR.

1. Tell us a little about yourself (when you first started in this ED or elsewhere). Introduction and Use of EHR

2. Perception: How long have you been using the current EHR? How do you like it? Have your perceptions changed over time? If they have changed then does this have anything to do with their familiarity with the system over time? Had it changed the way they do their daily task, in terms of their workflow (e.g., do they spend more time in the computer versus with patients)?

a. If they have problems, ask for examples.

b. If they like the current EHR, then also ask for examples.

3. Are there any functions of the EHR that you find problematic? a. If yes, please explain what barriers you have experienced. b. If no, what do you like about it?

4. EHRs are supposed to increase efficiency, effectiveness and safety. On a scale of 1 to 10 with 1 being the lowest and 10 being the highest, where would you rate the system you use on:

- Efficiency of getting work done in the ED.

- Effective quality of care in delivering quality care for your patients.

- Improvement in patient safety in comparison to the paper-based system used earlier.

\section{MU Performance Metrics}

5. As you know, we have several metrics to assess what is called "MU" in the ED and you are required to comply with them. Did you know about them? They are supposed to make some of the clinical processes more efficient.

6. In your opinion, do you think the use of EHR in the ED influenced any of these processes I am going to talk about: (You can probe further based on what they say. If they say yes, then ask how? If no, then ask to elaborate if processed could influence their work pattern).

a. Door to Doctor Time: Median time from patient's first entry into the ED to being seen by a physician.

b. Admit Decision Time: Median time from patient's first entry to the decision to admit from the ED.

c. Boarding Time: Median time for patient's arrival in the ED to their departure after being admitted (few clinicians provide responses on this metric).

d. Walk Out Rate: Patients who go through registration, but leave before being seen by a physician.

7. Do any of these indicators alter your work pattern in any way that you are aware of?

\section{Quality and Safety}

8. I'm going to read a statement to you: "One of the most important aspects of using health information technology such as EHRs, is to provide not only efficient and effective patient care, but also safe care. To what extent does this resonate with you personally in your ED practice? (Ask them to elaborate, as needed). 
Appendix B Coding categories and subcategories for qualitative analysis

\begin{tabular}{|c|c|c|}
\hline \multicolumn{2}{|l|}{ Category } & Scale used \\
\hline \multicolumn{2}{|c|}{ Perception about EHR used } & \multirow[t]{2}{*}{ Positive, neutral, negative } \\
\hline \multicolumn{2}{|c|}{ Changes in perception } & \\
\hline \multicolumn{2}{|c|}{ Time spent with patients } & $\begin{array}{l}\text { More time, equal time, } \\
\text { less time }\end{array}$ \\
\hline \multirow[t]{7}{*}{ EHR usability } & Clicks & \multirow[t]{7}{*}{ Frequency of response } \\
\hline & Multiple windows & \\
\hline & Difficulty maneuvering the system (navigation) & \\
\hline & Problems with access to required information & \\
\hline & Repetition of tasks & \\
\hline & Screen/Display clutter & \\
\hline & Useful functions & \\
\hline \multirow[t]{3}{*}{ Effect of EHR on } & Efficiency of work & \multirow{3}{*}{$\begin{array}{l}\text { Scale from } 1 \text { to } 10 \text {, with } 1 \\
\text { as the lowest and } 10 \text { as } \\
\text { the highest }\end{array}$} \\
\hline & Effective quality of care & \\
\hline & Safety compared with paper-based systems & \\
\hline \multirow{4}{*}{$\begin{array}{l}\text { MU compliance } \\
\text { criteria awareness }\end{array}$} & Door to diagnostic evaluation & \multirow[t]{4}{*}{ Positive, neutral, negative } \\
\hline & Admit decision time & \\
\hline & Time from arrival to ED departure for admitted patients (boarding) & \\
\hline & Patients leaving the ED without being seen & \\
\hline Impact of EHR on & Impact of MU requirements on workflow & Positive, neutral, negative \\
\hline
\end{tabular}

Abbreviations: ED, emergency department; EHR, electronic health record; MU, meaningful use. 